\title{
Gene Therapy for the Retinal Degeneration of Usher Syndrome Caused by Mutations in MYO7A
}

\author{
Vanda S. Lopes and David S. Williams \\ Stein Eye Institute, University of California at Los Angeles, Los Angeles, California 90095-7000 \\ Correspondence: dswilliams@ucla.edu
}

Usher syndrome is a deaf-blindness disorder. One of the subtypes, Usher 1B, is caused by loss of function of the gene encoding the unconventional myosin, MYO7A. A variety of different viral-based delivery approaches have been tested for retinal gene therapy to prevent the blindness of Usher 1B, and a clinical trial based on one of these approaches has begun. This review evaluates the different approaches.

U sher syndrome is mainly a recessive genetic disorder characterized by deafness and progressive retinal degeneration. It has been divided into types $1-3$, according to the severity and time course of the hearing impairment. Further subdivision has been based on genetic linkage (Williams 2008). Usher 1B, the most prevalent form of Usher type 1, is caused by mutations in the gene encoding the unconventional molecular motor, MYO7A. Its recessive inheritance suggests that Usher $1 \mathrm{~B}$ results from loss of protein function. Mutations have been found along the entire gene, some of which are predicted to be effective null mutations (Jacobson et al. 2011).

The loss of both hearing and vision makes Usher syndrome a particularly disabling disorder. Nowadays, the hearing deficiency can be addressed with the aid of cochlear implants, but the visual impairment has no treatment. In most cases, the deafness is congenital; Usher 1 patients are born profoundly deaf. Usher patients are therefore readily identified when infants, before onset of retinal degeneration, making them particularly good candidates for gene replacement therapy. The introduction of cDNA encoding functional MYO7A, before there is any retinal damage, should result in efficacious prevention. A phase 1 clinical trial has been approved by the Food and Drug Administration (FDA) and has been under way in the U.S. since 2012, and a second trial has been approved in France.

This review gives a historical account of preclinical work leading up to the clinical trials, and discusses some still unanswered questions, as well as the strengths and weaknesses of different viral-based strategies.

\section{MUTANT MYO7A: MOUSE MODEL AND MUTANT PHENOTYPES}

Mice carrying mutations in Myo7a, the Usher 1B ortholog, are known as shaker1. They were

Editors: Eric A. Pierce, Richard H. Masland, and Joan W. Miller

Additional Perspectives on Retinal Disorders: Genetic Approaches to Diagnosis and Treatment available at www.perspectivesinmedicine.org

Copyright (C) 2015 Cold Spring Harbor Laboratory Press; all rights reserved; doi: 10.1101/cshperspect.a017319

Cite this article as Cold Spring Harb Perspect Med 2015;5:a017319 
V.S. Lopes and D.S. Williams

identified readily by mouse geneticists, because of their head tossing, hyperactivity, and circling behavior, which result from cochlear and vestibular dysfunction (Gibson et al. 1995). Spontaneous or N-ethyl-N-nitrosourea (ENU)induced mutations have now resulted in approximately 10 different alleles of shaker1 (Mburu et al. 1997). None of the alleles presents retinal degeneration under normal light conditions, a common feature among most of the Usher 1 mouse models (Williams 2008). However, the identification of mutant phenotypes in the retina has provided relatively robust assays by which to test the introduction of functional MYO7A protein. Hence, the shaker1 mouse represents a useful diagnostic tool for testing the efficacy of retinal gene therapy in vivo. Most of such studies have used the Myo7a $a^{\text {sh1-4626SB }}$ allele, which possesses a premature stop codon that results in no detectable protein.

In the retina, MYO7A has been detected in the retinal pigment epithelium (RPE) and the photoreceptor cells. The majority of the protein is found in the RPE, where it localizes in the apical region (Hasson et al. 1995; Liu et al. 1997). In the photoreceptors, MYO7A is localized to the connecting cilium and periciliary region (Liu et al. 1997; Williams 2008); recently, it has also been reported to be present in the calycal processes of monkey and frog photoreceptors (Fig. 1) (Sahly et al. 2012).

MYO7A has been shown to be a functional actin-based motor (Udovichenko et al. 2002). Mutant phenotypes in shaker 1 retinas are consistent with its role as a molecular motor. The most obvious defect, and one that has proved to be the most useful in studies testing the efficacy of gene therapy, is the absence of melanosomes from the apical RPE (Fig. 1) (Liu et al. 1998). MYO7A associates with melanosomes via two linker proteins, MYRIP and RAB27A. Without MYO7A (or either of the linker proteins), the melanosomes are unable to move along actin filaments, and are thus absent from the apical RPE (Futter et al. 2004; Gibbs et al. 2004; Klomp et al. 2007; Lopes et al. 2007). The consequences of mislocalized melanosomes are not clear, but it has been suggested that they move more apically at the time of light onset, and perhaps facilitate phagosome ingestion and degradation (Futter et al. 2004). Melanosomes may also serve as a sink for damaging reactive species resulting from processes like lipid peroxidation (Schraermeyer 1999). The knockdown of MYO7A in human RPE cells has the same effect on melanosome motility as that found in shaker1 RPE cells (Gibbs et al. 2010).

MYO7A also associates with RPE phagosomes and contributes to their motility, with lack of MYO7A resulting in slowed degradation of these organelles (Gibbs et al. 2003; VS Lopes and DS Williams, unpubl.). More recently, MYO7A has been implicated in the lightdependent translocation of the retinoid isomerase, RPE65. Shaker1 retinas have a lower amount of RPE65, which is likely responsible for an observed protection from acute light damage (Lopes et al. 2011).

In shaker1 photoreceptors, detailed analysis by immunoelectron microscopy has shown that the ciliary plasma membrane has an abnormal accumulation of rhodopsin (Liu et al. 1999), suggesting a role for MYO7A in facilitating opsin delivery to the disk membranes of the photoreceptor outer segment.

Electrophysiological studies of shaker 1 mice indicated a slightly reduced a- and b-wave response (Libby and Steel 2001). More recently, in studying shaker1 mice on an albino background, a more significant electroretinogram (ERG) abnormality was observed, with a bwave reduction of $20 \%$ at $6 \mathrm{mo}$, and $\sim 27 \%$ at 12 mo of age. This change is accompanied by a progressive increase in the threshold of rod sensitivity to light, reaching $67 \%$ by $12 \mathrm{mo}$, and a delay in rod recovery after desensitization (Colella et al. 2013).

MYO7A has now been implicated in the translocation of transducin from the outer to the inner segment in response to light (Peng et al. 2011). In shaker1 mice, transducin translocation is impaired because of a shift in the activation threshold toward higher light intensities (Peng et al. 2011). Although this response is promising as read-out for MYO7A function in photoreceptors, it should be noted that, unlike the above mutant phenotypes, it has only been observed in one allele of shaker1 mice, 
Gene Therapy Approaches for Usher Syndrome Caused by Mutations in MYO7A

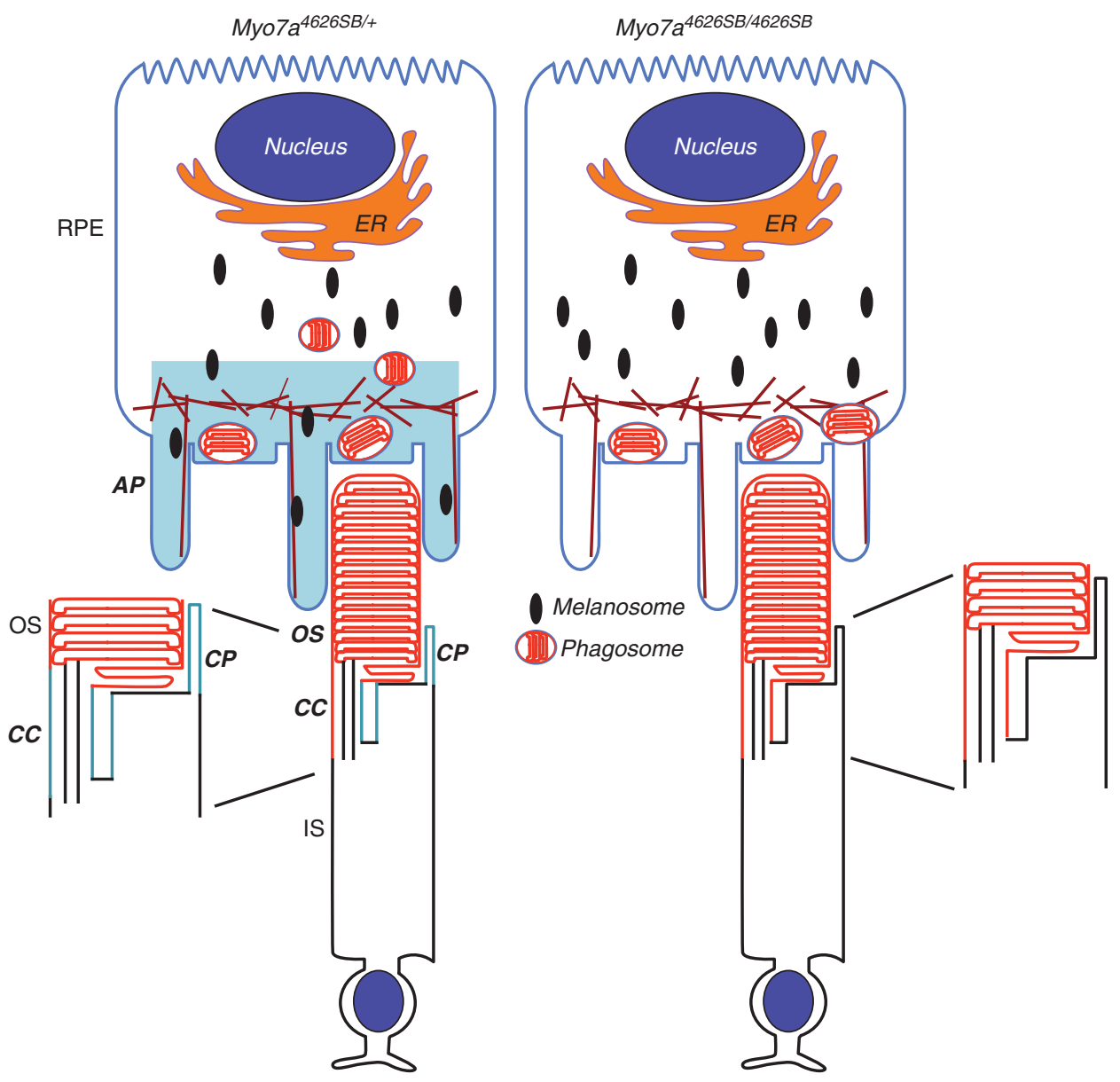

Figure 1. Diagram of MYO7A localization in the retina, and retinal mutant phenotypes identified in $M y o 7 a^{\text {shl-4626SB }}$ mice. MYO7A (blue) has been found in the apical region of the RPE, and in the connecting cilium, periciliary membrane, and calycal processes of the photoreceptors. In the mutant RPE, phagosomes accumulate in the apical processes, whereas melanosomes are found only in the cell body. An abnormal accumulation of opsin (red) is present in the connecting cilium of mutant photoreceptors. RPE, retinal pigment epithelial cell; AP, RPE apical processes; OS, outer segment; IS, inner segment; CC, connecting cilium; CP, calycal processes.

Myo7a $a^{\text {shl-11J }}$. The specific mutation underlying this allele, and the effect that the mutation has on protein structure and levels are not known, except that mutant MYO7A protein is detectable (Zallocchi et al. 2014). The same investigators have identified an increased susceptibility to light-induced photoreceptor degeneration in Myo7a $a^{\text {shl-11J }}$ mice (Peng et al. 2011), which is the converse finding to that mentioned above for the null shakerl allele, $M y o 7 a^{\text {sh1-4626SB }}$ (Lopes et al. 2011).
The above mutant phenotypes provide assays to test therapeutic efficacy in shaker1 mice. In particular, for gene therapy, mutant phenotype correction tests the presence of a fully functional MYO7A protein. The absence of retinal degeneration in this animal model is actually beneficial for such studies, because measurements can be made without concern of interference from secondary effects of cell death events. The use of a differential response to high light exposure should clearly not be used until 
V.S. Lopes and D.S. Williams

the conflicting findings on the response are resolved.

\section{GENE THERAPY WITH LENTIVIRUSES}

As discussed later, adeno-associated viruses (AAV) have been widely used for viral delivery in gene therapy; however, the size of a gene that can be encapsulated into AAV has been reported to be limited to $\sim 5 \mathrm{~kb}$ (Grieger and Samulski 2005). MYO7A, is a large gene of $\sim 100 \mathrm{Mb}$ and a cDNA of nearly $7 \mathrm{~kb}$, so that an alternative strategy was sought for its delivery. Among the available viral gene delivery options, lentiviruses have a cargo capacity of $\sim 10 \mathrm{~kb}$ and can infect postmitotic cells. Genes delivered by lentiviruses are integrated into the host genome, which typically assures long-lived gene expression, although poses a risk of insertional mutagenesis.

\section{Human Immunodeficiency Virus (HIV)}

In the late 1990s, third generation HIV-derived lentiviruses were shown to possess a number of important biosafety features (Verma and Weitzman 2005) and be effective for transduction of rodent RPE and photoreceptors (Miyoshi et al. 1997; Takahashi et al. 1999). The first gene therapy studies with MYO7A used the same third generation, self-inactivating, and HIV-derived lentiviral vectors (Hashimoto et al. 2007). Expression was driven by either cytomegalovirus (CMV) or a chimeric promoter, composed of CMV and $160 \mathrm{bp}$ located upstream of the ATG signal in the MYO7A gene. Mutant phenotypes in the RPE, both in primary cell culture and in vivo, following subretinal injection, were corrected, showing the ability of HIV-derived lentiviruses to encapsulate MYO7A cDNA and effect expression of functional protein in infected cells. Correction of opsin distribution in the connecting cilia of shaker 1 mice was also observed (Hashimoto et al. 2007).

Although this study showed successful transduction and expression of MYO7A in the targeted cells, it also highlighted the importance of the level of protein expression. With the chimeric promoter, the expression level of MYO7A in vivo was observed to vary among different RPE cells, resulting in a mosaic pattern of rescue of melanosome localization. First, the cell-tocell variation in expression indicates a limitation with an integrating virus, because it is likely a result of variation in the number and site(s) of integration into the host genome. Second, it stresses the importance of sufficiently high expression to achieve rescue. This latter point needs to be balanced with a serious problem from overexpression. With the full CMV promoter, RPE cell death was observed in relation to high levels of expression of MYO7A, especially in primary cell culture (Hashimoto et al. 2007).

Photoreceptor cells have been reported to be transduced inefficiently by lentiviruses. It is thought that, especially in mouse retinas, where the photoreceptor cells are packed very densely, a relatively large virus has limited access to the photoreceptor cells (Gruter et al. 2005). This restriction is more of a problem for genes that are normally expressed at a higher level in photoreceptors than MYO7A. Indeed, it might provide some compensation for the abnormal regulation of MYO7A expression effected by ubiquitous promoters, because the normal expression level of MYO7A in photoreceptor cells is so much less than that in the RPE cells.

\section{Equine Infectious Anemia Virus (EIAV)}

Equine infectious anemia virus (EIAV) lentiviruses have been used for gene therapy of several cell types. Studies with the ABCA4 gene, which is mutated in recessive Stargardt's macular degeneration, have shown that EIAV is able to encapsulate a large gene and transduce photoreceptors cells (Kong et al. 2008). More recent studies with EIAV delivery of MYO7A cDNA, under the control of a CMV promoter, have been performed with Myo7ash1-11J mice and Rhesus monkeys (Zallocchi et al. 2014). These studies have formed preclinical support for the clinical trials underway, using the same viral delivery approach.

Delivery of the viral vector to the subretinal space led to expression of human MYO7A in the RPE and photoreceptor cells, as shown 
Gene Therapy Approaches for Usher Syndrome Caused by Mutations in MYO7A

by immunofluorescence microscopy. Because $M y o 7 a^{\text {sh1-11J }}$ mice express significant levels of mutant MYO7A, and the monkeys were wildtype (WT), EIAV-CMV-MYO7A expression was detected by diluting MYO7A antibodies so that endogenous MYO7A could not be detected. Thus, the viral MYO7A expression appears to be much greater than WT levels. Moreover, MYO7A was detected in the photoreceptor outer segments, which is an abnormal localization. Given the findings of cell death resulting from overexpression of MYO7A driven by HIVCMV-MYO7A (Hashimoto et al. 2007), this expression level is a concern. In photoreceptors, WT MYO7A is only present in the connecting cilium region and is usually barely detectable by epifluorescence immunomicroscopy (Liu et al. 1997).

Functional rescue was tested by studying transducin translocation profiles, which show some restoration in Myo7a $a^{\text {shl-11J }}$ photoreceptors. However, the majority of transducin is still retained in the outer segment, indicating incomplete rescue, even with the presumably high levels of WT MYO7A. Experiments were also performed to test for the effect of EIAV-CMV-MYO7A on susceptibility to lightinduced degeneration. However, there was no difference between mice injected with EIAVCMV-MYO7A and mice injected with saline, after maintenance under a daily cycle of $12 \mathrm{~h}$ $1500 \operatorname{lux} / 12 \mathrm{~h}$ dark for 3 mo. This result suggests that the viral vector alone may have some retinal toxicity, as the investigators themselves note. Biodistribution and toxicity studies showed that the EIAV-CMV-MYO7A is tolerated well in monkeys over a period of $3 \mathrm{mo}$, and that a single subretinal dose does not spread into the body, although it can raise a moderate local inflammatory response (Zallocchi et al. 2014).

In conclusion, studies show that both HIV and EIAV can be used to deliver MYO7A to RPE and photoreceptor cells. Both lentiviral approaches also appear to be capable of rescuing mutant phenotypes, although it is unfortunate that EIAV-CMV-MYO7A, which is being used in clinical trials, has not been tested for correction of phenotypes that have been identified in more than one laboratory, and with a characterized shaker1 null allele. A comparison of the two lentiviruses in vitro indicated that transgene expression was similar, but that expression derived from EIAV was more likely to be reduced over time because of instability of the RNAtranscripts (O’Rourke et al. 2002).

\section{GENE THERAPY WITH ADENO-ASSOCIATED VIRUSES}

AAV has been the most extensively studied viral tool for retinal gene therapy. These viruses can target postmitotic cells efficiently. They remain episomal, thus avoiding the insertional mutagenesis risks of lentiviruses, but still result in prolonged expression. The first retinal gene therapy approach was for treatment of Leber's congenital amaurosis (LCA2), which is caused by mutations in RPE65. In these studies, AAV was used to deliver normal RPE65 CDNA to the RPE cells, and the safety and efficacy of this treatment has now been shown independently in various clinical trials (Bainbridge et al. 2008; Cideciyan et al. 2008, 2009; Hauswirth et al. 2008; Maguire et al. 2008; Jacobson et al. 2012; Testa et al. 2013). However, as noted above, its limited cargo capacity has been seen as an impediment in retinal degenerations requiring the delivery of large genes (Grieger and Samulski 2005).

\section{AAV Single Vectors}

A study by Alloca et al. (2008) indicated the potential of AAV vectors to deliver genes that are $>5 \mathrm{~kb}$, like $M Y O 7 A$ and $A B C A 4$, to retinal cells. Although the mechanism by which such oversized AAV transduction occurs is unknown, studies on the encapsulation of large genes by AAV has shown that the vectors contain a heterogeneous population of truncated genomes that are mostly $<5 \mathrm{~kb}$ (Dong et al. 2010; Lai et al. 2010; Wu et al. 2011). Hence, the gene is fragmented, and for functional delivery must be reconstituted by homologous recombination inside a cell (Dong et al. 2010).

Studies on the ability of oversized AAV vectors to generate MYO7A in HEK293 cells (Colella et al. 2013) and RPE primary cultures 
V.S. Lopes and D.S. Williams

derived from $M y 07 a^{\text {sh1-4626SB }}$ mice (Lopes et al. 2013) showed that they can indeed produce full length protein, with no major evidence of truncated products. In the RPE cultures from $M y o 7 a^{\text {sh1-4626SB }}$ mice, the expression level of MYO7A was comparable to that in cultures from heterozygous control littermates. Moreover, following injection into the subretinal space of Myo7a $a^{\text {sh1-4626SB }}$ mice, MYO7A could be detected at WT levels in the RPE and photoreceptor cells, and at higher levels with more concentrated virus (Lopes et al. 2013). Western blot analysis of posterior eye segments, after subretinal injection, showed that expression persists for at least 15 mo (Colella et al. 2013). Two separate studies have shown that mutant retinal phenotypes of $M y o 7 a^{\text {sh1-4626SB }}$ mice could be rescued both in the RPE and photoreceptors. In a detailed study with two different serotypes, AAV2 and AAV5, melanosomes were observed in the RPE apical processes, similar to WT control mice, and the distribution of opsin in the connecting cilia of the photoreceptors was restored to normal, indicating functional protein was made in both cell types (Lopes et al. 2013). These observations were reproduced in a study, using AAV5, which showed, in addition, that the rod light desensitization threshold could be restored to normal levels (Colella et al. 2013).

\section{AAV Dual Vectors}

The major concern with oversized AAV vectors for clinical use is the apparent randomness in the resulting sizes of genomes delivered to the cells. A strategy to overcome this problem is to divide a gene or cDNA, such as MYO7A, into two pieces and have each piece contained within a separate AAV vector. Once inside the cells, concatemerization and homologous recombination of the two pieces will lead to the formation of full-length mRNA and protein. As described by Trapani et al. (2014), strategies include: (1) trans-splicing, where a splice donor site is introduced at the $3^{\prime}$ end of the first half of the gene, and an acceptor donor site is introduced at the $5^{\prime}$ end of the second half, resulting in full length mRNA by head to tail concate- merization of the two halves; (2) overlapping halves, where homologous overlapping sequences are introduced in similar positions as those for the trans-splice sites, and will lead to homologous recombination of the two parts in cells; and (3) hybrid alternative, where a known exogenous recombinogenic region, such as alkaline phosphatase (AP), is added to the transsplicing vectors.

Our group has initially compared oversized single AAV2 and AAV5 vectors with an overlapping AAV2 dual vector. In primary cultures of RPE cells, we found that the oversized vector outperformed the dual system, in terms of both the average level of MYO7A protein made and the consistency of protein expression among the cells. A significant concern with the dual vector system was that, while most cells had negligible levels of MYO7A, a few cells had very high levels, and had clearly become abnormal (Lopes et al. 2013). Following subretinal injections of $M y o 7 a^{\text {sh1-4626SB }}$ mice, the overlapping dual vector was much less effective at correcting mutant phenotypes (Lopes et al. 2013). Since this study, additional reports have compared the different dual AAV vector approaches for MYO7A cDNA delivery.

In a study conducted by Trapani et al. (2014), the highest expression level was obtained with an AAV hybrid vector (AK), using a sequence from the $\mathrm{F} 1$ phage genome as the recombinogenic region. Interestingly, all AAV2 dual approaches, except the use of an AP recombinogenic hybrid, resulted in higher levels of MYO7A expression in HEK293 cells compared with the oversized single AAV2 vector, but a comparison with retinal cells was not made. Importantly, Trapani et al. (2014) found that the levels of protein expression were more variable when using the dual vectors. Consistent with the findings of Lopes et al. (2013), treatment of Myo7ash1-4626SB mice with AAV dual vectors resulted in only a mosaic effect of RPE cells with corrected melanosome localization (Trapani et al. 2014). Still, the overlapping strategy was more efficacious in the RPE, than in photoreceptors, which may be related to the low homologous recombination that occurs in the postmitotic neurons (Fishel et al. 2007). 
Gene Therapy Approaches for Usher Syndrome Caused by Mutations in MYO7A

Western blot analysis of posterior eye segments from treated $M y o 7 a^{\text {shl-4626SB }}$ mice showed that the trans-splicing and AK hybrid AAV dual vectors resulted in only $\sim 20 \%$ of the MYO7A level found in heterozygous littermates, and correction of a photoreceptor phenotype could not be determined (Trapani et al. 2014).

In another study, Dyka et al. (2014) reported slightly different outcomes. In addition to the methods attempted by Trapani et al. (2014), this group tested a construct in which intronic splice sites from the native MYO7A gene were included. However, this additional approach resulted in very low levels of MYO7A expression. Dyka et al. found that an AP hybrid $\mathrm{AAV}$ vector gave the highest expression level of MYO7A, but it also generated a mix of correct and mutant sequences, which were not detected in the other approaches. When injected into WT mice, this vector resulted in abnormal levels of MYO7A in the photoreceptors, and retinal degeneration. The best performing in vivo system in this group's hands seemed to be the overlapping approach. Despite the promising results with overlapping AAV8 dual vectors, no study was conducted with shaker 1 mice, so that the functionality of the protein could not be made. In addition, representative images shown by the investigators raise concerns about the distribution and levels of
MYO7A produced, as strong signal is evident throughout the inner segment and outer segments (Dyka et al. 2014).

Therefore, so far, dual AAV vector approaches remain problematic. A major emphasis has been on achieving a high expression level of MYO7A. However, a fundamental problem appears to be the variation in expression level among retinal cells. To achieve sufficient expression in most cells, some cells will express at such high levels as to be toxic. A further problem is the expression of partial MYO7A protein. Published western blots indicate the additional presence of a lower mass polypeptide, and studies with fluorescent reporters (GFP and RFP) indicated that the fraction of cells cotransduced is actually less than half (Trapani et al. 2014). Ironically, the presence of partial MYO7A polypeptides has been the concern for the oversized single AAV vector approach, and a justification for testing dual AAV vectors. Yet, at least in RPE cells, transduced with single AAV2 or AAV5, carrying MYO7A, only full-length MYO7A was detected (Lopes et al. 2013).

\section{WHICH ISOFORM OF MYO7A?}

The use of a cDNA in gene therapy defines the single isoform of the gene that will be expressed. Yet, like many genes, the MYO7A gene is alter-

Table 1. Comparison of different strategies for viral delivery of MYOTA in Usher 1B retinal gene therapy

\begin{tabular}{|c|c|c|c|c|c|c|}
\hline & \multicolumn{2}{|c|}{ Lentivirus } & \multicolumn{4}{|c|}{ Adeno-associated virus } \\
\hline & HIV-based & EIAV-based & $\begin{array}{l}\text { AAV2 } \\
\text { AAV5 }\end{array}$ & $\begin{array}{l}\text { AAV2 } \\
\text { AAV8 }\end{array}$ & AAV8 & AAV8 \\
\hline Myo7a cDNA encapsulation & Single & Single & Single $^{a}$ & Dual overlapping & $\begin{array}{l}\text { Dual } \\
\text { trans-splicing }\end{array}$ & $\begin{array}{l}\text { Dual } \\
\text { hybrid }\end{array}$ \\
\hline Genome integration & Yes & Yes & No & No & No & No \\
\hline Retinal cell layer targeted & RPE mainly & $\begin{array}{l}\text { RPE } \\
\text { PR }\end{array}$ & $\begin{array}{l}\text { RPE } \\
\text { PR }\end{array}$ & $\begin{array}{l}\text { RPE } \\
\text { PR }\end{array}$ & $\begin{array}{l}\text { RPE } \\
\text { PR }\end{array}$ & $\begin{array}{l}\text { RPE } \\
\text { PR }\end{array}$ \\
\hline Phenotype correction mouse & & & & & & \\
\hline $\begin{array}{l}\text { RPE } \\
\text { PR }\end{array}$ & $\begin{array}{l}\text { Mosaic }^{\mathrm{b}} \\
\text { Yes }^{\mathrm{b}}\end{array}$ & $\begin{array}{l}\text { Unknown } \\
\text { Yes }^{f}\end{array}$ & $\begin{array}{l}\text { Yes }^{\mathrm{c}, \mathrm{d}} \\
\text { Yes }^{\mathrm{c}, \mathrm{d}}\end{array}$ & $\begin{array}{l}\text { Mosaic }{ }^{\mathrm{c}, \mathrm{e}} \\
\text { Yes }^{\mathrm{c}, \mathrm{e}}\end{array}$ & $\begin{array}{l}\text { Mosaic }^{\mathrm{e}} \\
\text { Unknown }\end{array}$ & $\begin{array}{l}\text { Mosaic } \\
\text { Unknown }\end{array}$ \\
\hline
\end{tabular}

${ }^{\mathrm{a}}$ Although not shown specifically for MYO7A, large genes are fragmented to be accommodated by AAV.

${ }^{\mathrm{b}}$ Hashimoto et al. (2007), mosaic effect in RPE maybe because of variable expression levels from variable gene integration. ${ }^{c}$ Lopes et al. (2013).

${ }^{\mathrm{d}}$ Colella et al. (2013).

${ }^{\mathrm{e}}$ Trapani et al. (2014).

fallocchi et al. (2014). 
V.S. Lopes and D.S. Williams

natively spliced. Two closely related, long isoforms of MYO7A, isoforms 1 and 2, have been reported to be expressed in the retina (Weil et al. 1996). They differ by the expression of a 114-bp region in the $5^{\prime}$ end of exon 34 . The resulting 38 amino acids in isoform 1 are located in the FERM1 domain, and may impact interaction with another Usher 1 protein, SANS (Adato et al. 2005; Wu et al. 2011). It may also affect overall protein structure and stability. Presently, no discrimination has been made in the use of isoform 1 or 2 for gene therapy trials, despite the lack of evidence toward a majority use of one or the other by retinal cells. Studies by our group and Dyka et al. (2014) have focused on isoform 2, while studies from Auricchio's group (Colella et al. 2013; Trapani et al. 2014) have used isoform 1 . Thus, by accident, it appears that either isoform might do. However, it would seem that more definitive studies should be performed to determine which cDNA might be better for future clinical trials.

\section{CONCLUDING REMARKS}

Avariety of viral-based delivery approaches have been tested for Usher 1B retinal gene therapy (summarized in Table 1), and most have been shown to be efficacious. Each has its advantages and disadvantages. The large size of the MYO7A cDNA prompted the use of lentiviruses, but integration of the gene poses a risk of insertional mutagenesis and has been shown to result in cell-to-cell variation in expression level. Clinical trials have been started with EIAV-CMV$M Y O 7 A$, but the preclinical studies to test efficacy have been very limited. Recent studies on the use of AAV for the delivery of MYO7A have been encouraging; especially because of the relatively established success of AAV in gene therapy for inherited retinal diseases such as LCA2. $\mathrm{AAV}$ remains episomal, thus avoiding the insertional mutagenesis risks of lentiviruses. However, the fragmentation that occurs with single $\mathrm{AAV}$ vectors, and the variable expression levels found with dual AAV vectors are drawbacks. One alternative that may prove to be optimal for large genes like MYO7A is the use of nonintegrating lentiviruses; integrase-deficient vec- tors that can transduce retinal cells are able to persist as episomal DNA (Yáñez-Muñoz et al. 2006). However, such studies have yet to be reported.

\section{ACKNOWLEDGMENTS}

D.S.W. is supported by grants from the National Eye Institute and a Jules and Doris Stein Professorship from the Research to Prevent Blindness.

\section{REFERENCES}

Adato A, Michel V, Kikkawa Y, Reiners J, Alagramam KN, Weil D, Yonekawa H, Wolfrum U, El-Amraoui A, Petit C. 2005. Interactions in the network of Usher syndrome type 1 proteins. Hum Mol Genet 14: 347-356.

Allocca M, Doria M, Petrillo M, Colella P, Garcia-Hoyos M, Gibbs D, Kim SR, Maguire A, Rex TS, Di Vicino U, et al. 2008. Serotype-dependent packaging of large genes in adeno-associated viral vectors results in effective gene delivery in mice. J Clin Invest 118: 1955-1964.

Bainbridge J, Smith A, Barker S, Robbie S, Henderson R, Balaggan K, Viswanathan A, Holder GE, Stockman A, Tyler N, et al. 2008. Effect of gene therapy on visual function in Leber's congenital amaurosis. N Engl J Med 358: 2231-2239.

Cideciyan A, Aleman T, Boye S, Schwartz S, Kaushal S, Roman A, Pang JJ, Sumaroka A, Windsor EA, Wilson JM, et al. 2008. Human gene therapy for RPE65 isomerase deficiency activates the retinoid cycle of vision but with slow rod kinetics. Proc Natl Acad Sci 105: 1511215117.

Cideciyan AV, Hauswirth WW, Aleman TS, Kaushal S, Schwartz SB, Boye SL, Windsor EA, Conlon TJ, Sumaroka A, Pang JJ, et al. 2009. Human RPE65 gene therapy for Leber congenital amaurosis: Persistence of early visual improvements and safety at 1 year. Hum Gene Ther 20: 999-1004.

Colella P, Sommella A, Marrocco E, Di Vicino U, Polishchuk E, Garrido MG, Seeliger MW, Polishchuk R, Auricchio A. 2013. Myosin7a deficiency results in reduced retinal activity which is improved by gene therapy. PLOS ONE 8: e72027.

Dong B, Nakai H, Xiao W. 2010. Characterization of genome integrity for oversized recombinant AAV vector. Mol Ther 18: $87-92$.

Dyka FM, Boye SL, Chiodo VA, Hauswirth WW, Boye SE. 2014. Dual adeno-associated virus vectors result in efficient in vitro and in vivo expression of an oversized gene, MYO7A. Hum Gene Ther Methods 25: 166-177.

Fishel ML, Vasko MR, Kelley MR. 2007. DNA repair in neurons: So if they don't divide what's to repair? Mutat Res 614: 24-36.

Futter CE, Ramalho JS, Jaissle GB, Seeliger MW, Seabra MC. 2004. The role of Rab27a in the regulation of melanosome distribution within retinal pigment epithelial cells. Mol Biol Cell 15: 2264-2275. 
Gibbs D, Kitamoto J, Williams DS. 2003. Abnormal phagocytosis by retinal pigmented epithelium that lacks myosin VIIa, the Usher syndrome 1B protein. Proc Natl Acad Sci 100: 6481-6486.

Gibbs D, Azarian SM, Lillo C, Kitamoto J, Klomp AE, Steel KP, Libby RT, Williams DS. 2004. Role of myosin VIIa and Rab27a in the motility and localization of RPE melanosomes. J Cell Sci 117: 6473-6483.

Gibbs D, Diemer T, Khanobdee K, Hu J, Bok D, Williams DS. 2010. Function of MYO7A in the human RPE and the validity of shaker1 mice as a model for Usher syndrome 1B. Invest Ophthalmol Vis Sci 51: 1130-1135.

Gibson F, Walsh J, Mburu P, Varela A, Brown KA, Antonio M, Beisel KW, Steel KP, Brown SD. 1995. A type VII myosin encoded by the mouse deafness gene shaker- 1 . Nature 374: 62-64.

Grieger J, Samulski R. 2005. Packaging capacity of adenoassociated virus serotypes: Impact of larger genomes on infectivity and postentry steps. J Virol 79: $9933-$ 9944.

Gruter O, Kostic C, Crippa SV, Perez MT, Zografos L, Schorderet DF, Munier FL, Arsenijevic Y. 2005. Lentiviral vector-mediated gene transfer in adult mouse photoreceptors is impaired by the presence of a physical barrier. Gene Ther 12: 942-947.

Hashimoto T, Gibbs D, Lillo C, Azarian SM, Legacki E, Zhang XM, Yang XJ, Williams DS. 2007. Lentiviral gene replacement therapy of retinas in a mouse model for Usher syndrome type 1B. Gene Ther 14: 584-594.

Hasson T, Heintzelman MB, Santos-Sacchi J, Corey DP, Mooseker MS. 1995. Expression in cochlea and retina of myosin VIIa, the gene product defective in Usher syndrome type 1B. Proc Natl Acad Sci 92: 9815-9819.

Hauswirth WW, Aleman TS, Kaushal S, Cideciyan AV, Schwartz SB, Wang L, Conlon TJ, Boye SL, Flotte TR, Byrne BJ, et al. 2008. Treatment of Leber congenital amaurosis due to RPE65 mutations by ocular subretinal injection of adeno-associated virus gene vector: Shortterm results of a phase I trial. Hum Gene Ther 19: 979990.

Jacobson SG, Cideciyan AV, Gibbs D, Sumaroka A, Roman AJ, Aleman TS, Schwartz SB, Olivares MB, Russell RC, Steinberg JD, et al. 2011. Retinal disease course in Usher syndrome $1 \mathrm{~B}$ due to MYO7A mutations. Invest Ophthalmol Vis Sci 52: 7924-7936.

Jacobson SG, Cideciyan AV, Ratnakaram R, Heon E, Schwartz SB, Roman AJ, Peden MC, Aleman TS, Boye SL, Sumaroka A, et al. 2012. Gene therapy for Leber congenital amaurosis caused by RPE65 mutations: Safety and efficacy in 15 children and adults followed up to 3 years. Arch Ophthalmol 130: 9-24.

Klomp AE, Teofilo K, Legacki E, Williams DS. 2007. Analysis of the linkage of MYRIP and MYO7A to melanosomes by RAB27A in retinal pigment epithelial cells. Cell Motil Cytoskeleton 64: 474-487.

Kong J, Kim SR, Binley K, Pata I, Doi K, Mannik J, ZernantRajang J, Kan O, Iqball S, Naylor S, et al. 2008. Correction of the disease phenotype in the mouse model of Stargardt disease by lentiviral gene therapy. Gene Ther 15: 13111320 .
Lai Y, Yue Y, Duan D. 2010. Evidence for the failure of adenoassociated virus serotype 5 to package a viral genome $\geq 8.2 \mathrm{~kb}$. Mol Ther 18: 75-79.

Libby RT, Steel KP. 2001. Electroretinographic anomalies in mice with mutations in Myo7a, the gene involved in human Usher syndrome type 1B. Invest Ophthalmol Vis Sci 42: $770-778$.

Liu X, Vansant G, Udovichenko IP, Wolfrum U, Williams DS. 1997. Myosin VIIa, the product of the Usher 1B syndrome gene, is concentrated in the connecting cilia of photoreceptor cells. Cell Motil Cytoskeleton 37: 240252.

Liu X, Ondek B, Williams DS. 1998. Mutant myosin VIIa causes defective melanosome distribution in the RPE of shaker-1 mice. Nat Genet 19: 117-118.

Liu X, Udovichenko IP, Brown SD, Steel KP, Williams DS. 1999. Myosin VIIa participates in opsin transport through the photoreceptor cilium. J Neurosci 19: 62676274.

Lopes VS, Ramalho JS, Owen DM, Karl MO, Strauss O, Futter CE, Seabra MC. 2007. The ternary Rab27aMyrip-Myosin VIIa complex regulates melanosome motility in the retinal pigment epithelium. Traffic 8: 486499.

Lopes VS, Gibbs D, Libby RT, Aleman TS, Welch DL, Lillo C, Jacobson SG, Radu RA, Steel KP, Williams DS. 2011. The Usher 1B protein, MYO7A, is required for normal localization and function of the visual retinoid cycle enzyme, RPE65. Hum Mol Genet 20: $2560-$ 2570.

Lopes VS, Boye SE, Louie CM, Boye S, Dyka F, Chiodo V, Fofo H, Hauswirth WW, Williams DS. 2013. Retinal gene therapy with a large MYO7A cDNA using adeno-associated virus. Gene Ther 20: 824-833.

Maguire A, Simonelli F, Pierce E, Pugh E, Mingozzi F, Bennicelli J, Banfi S, Marshall KA, Testa F, Surace EM, et al. 2008. Safety and efficacy of gene transfer for Leber's congenital amaurosis. $N$ Engl J Med 358: $2240-$ 2248.

Mburu P, Liu XZ, Walsh J, Saw D Jr, Cope MJ, Gibson F, Kendrick-Jones J, Steel KP, Brown SD. 1997. Mutation analysis of the mouse myosin VIIA deafness gene. Genes Funct 1: 191-203.

Miyoshi H, Takahashi M, Gage FH, Verma IM. 1997. Stable and efficient gene transfer into the retina using an HIVbased lentiviral vector. Proc Natl Acad Sci 94: 1031910323.

O'Rourke JP, Newbound GC, Kohn DB, Olsen JC, Bunnell BA. 2002. Comparison of gene transfer efficiencies and gene expression levels achieved with equine infectious anemia virus- and human immunodeficiency virus type 1-derived lentivirus vectors. J Virol 76: $1510-1515$.

Peng YW, Zallocchi M, Wang WM, Delimont D, Cosgrove D. 2011. Moderate light-induced degeneration of rod photoreceptors with delayed transducin translocation in shaker1 mice. Invest Ophthalmol Vis Sci 52: 64216427.

Sahly I, Dufour E, Schietroma C, Michel V, Bahloul A, Perfettini I, Pepermans E, Estivalet A, Carette D, Aghaie A, et al. 2012. Localization of Usher 1 proteins to the photo- 
V.S. Lopes and D.S. Williams

receptor calyceal processes, which are absent from mice. J Cell Biol 199: 381-399.

Schraermeyer UHK. 1999. Current understanding on the role of retinal pigment epithelium and its pigmentation. Pigment Cell Res 12: 219-236.

Takahashi M, Miyoshi H, Verma IM, Gage FH. 1999. Rescue from photoreceptor degeneration in the $r d$ mouse by human immunodeficiency virus vector-mediated gene transfer. J Virol 73: 7812-7816.

Testa F, Maguire AM, Rossi S, Pierce EA, Melillo P, Marshall K, Banfi S, Surace EM, Sun J, Acerra C, et al. 2013.

Three-year follow-up after unilateral subretinal delivery of adeno-associated virus in patients with Leber congenital amaurosis type 2. Ophthalmology 120: 12831291.

Trapani I, Colella P, Sommella A, Iodice C, Cesi G, de Simone S, Marrocco E, Rossi S, Giunti M, Palfi A, et al. 2014. Effective delivery of large genes to the retina by dual AAV vectors. EMBO Mol Med 6: 194-211.

Udovichenko IP, Gibbs D, Williams DS. 2002. Actin-based motor properties of native myosin VIIa. J Cell Sci 115: $445-450$.
Verma I, Weitzman M. 2005. Gene therapy: Twenty-first century medicine. Annu Rev Biochem 74: 711-738.

Weil D, Levy G, Sahly I, Levi-Acobas F, Blanchard S, ElAmraoui A, Crozet F, Philippe H, Abitbol M, Petit C. 1996. Human myosin VIIA responsible for the Usher 1B syndrome: A predicted membrane-associated motor protein expressed in developing sensory epithelia. Proc Natl Acad Sci 93: 3232-3237.

Williams DS. 2008. Usher syndrome: Animal models, retinal function of Usher proteins, and prospects for gene therapy. Vision Res 48: 433-441.

Wu L, Pan L, Wei Z, Zhang M. 2011. Structure of MyTH4FERM domains in myosin VIIa tail bound to cargo. Science 331: 757-760.

Yáñez-Muñoz R, Balaggan K, MacNeil A, Howe S, Schmidt M, Smith A, Buch P, MacLaren R, Anderson P, Barker S, et al. 2006. Effective gene therapy with nonintegrating lentiviral vectors. Nat Med 12: 348-353.

Zallocchi M, Binley K, Lad Y, Ellis S, Widdowson P, Iqball S, Scripps V, Kelleher M, Loader J, Miskin JP, et al. 2014. EIAV-based retinal gene therapy in the shaker1 mouse model for Usher syndrome type 1B: Development of UshStat. PLoS ONE 9: e94272. 


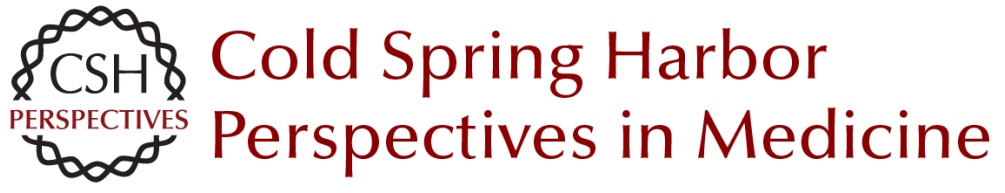

\title{
Gene Therapy for the Retinal Degeneration of Usher Syndrome Caused by Mutations in MYO7A
}

\author{
Vanda S. Lopes and David S. Williams
}

Cold Spring Harb Perspect Med 2015; doi: 10.1101/cshperspect.a017319 originally published online January 20, 2015

\section{Subject Collection Retinal Disorders: Genetic Approaches to Diagnosis and Treatment}

Trial by "Firsts": Clinical Trial Design and Regulatory Considerations in the Development and Approval of the First AAV Gene Therapy

Product in the United States

Kathleen Z. Reape and Katherine A. High

Immunology of Retinitis Pigmentosa and Gene Therapy-Associated Uveitis

Paul Yang, Debarshi Mustafi and Kathryn L. Pepple

Developing New Vectors for Retinal Gene Therapy Emilia A. Zin, Bilge E. Ozturk, Deniz Dalkara, et al.

Beyond the NEI-VFQ: Recent Experience in the Development and Utilization of Patient-Reported Outcomes for Inherited Retinal Diseases

Todd Durham, Judit Banhazi, Francesco Patalano, et al.

Electronic Retinal Prostheses Daniel Palanker

Alternative RNA Splicing in the Retina: Insights and Perspectives Casey J. Keuthan, Sadik Karma and Donald J. Zack

X-Linked Retinoschisis

Cristy A. Ku, Lisa W. Wei and Paul A. Sieving

A Systematic Review of Optogenetic Vision Restoration: History, Challenges, and New Inventions from Bench to Bedside Antonia Stefanov and John G. Flannery
Lessons Learned from the Development of the

First FDA-Approved Gene Therapy Drug, Voretigene Neparvovec-rzyl Jean Bennett and Albert M. Maguire

Therapeutic Gene Editing in Inherited Retinal Disorders Jinjie Ling, Laura A. Jenny, Ashley Zhou, et al.

Cell-Based Therapies: Strategies for Regeneration Marina Pavlou and Thomas A. Reh

The Importance of Natural History Studies in Inherited Retinal Diseases Allison Ayala, Janet Cheetham, Todd Durham, et al.

\section{Photoreceptor Cell Replacement Using Pluripotent Stem Cells: Current Knowledge and Remaining Questions} Christelle Monville, Olivier Goureau and Karim Ben M'Barek

iPSC-RPE in Retinal Degeneration: Recent Advancements and Future Perspectives Tadao Maeda and Masayo Takahashi

Retinal Degeneration Animal Models in BardetBiedl Syndrome and Related Ciliopathies Clarisse Delvallée and Hélène Dollfus

Mobility Testing and Other Performance-Based Assessments of Functional Vision in Patients with Inherited Retinal Disease

Daniel Chung, Colas Authié and Laure Blouin

For additional articles in this collection, see http://perspectivesinmedicine.cshlp.org/cgi/collection/ 
For additional articles in this collection, see http://perspectivesinmedicine.cshlp.org/cgi/collection/ 